\title{
LAS MARCAS EN LOS DICCIONARIOS GENERALES DE LENGUA
}

\section{Bonifacio RODRÍGUEZ DÍEZ}

\author{
Universidad de León
}

La REAL ACADEMIA EsPAÑOla (DRAE-1992: s.v. diccionario) define así la palabra diccionario: "(Del b.lat. dictionarium.) $\mathrm{m}$. Libro en el que se recogen y explican de forma ordenada voces de una o más lenguas, de una ciencia o materia determinada. 2. Catálogo numeroso de noticias importantes de un mismo género, ordenado alfabéticamente. DICCIONARIO bibliográfico, biográfico, geográfico". Este artículo del Diccionario de la R.A.E. sobre el diccionario presenta dos acepciones: una, más propia; y otra, resumidora de todos los posibles objetos denominados diccionarios. No obstante, la Real Academia Española, consciente de que la segunda acepción puede no estar bien redactada, echa mano de algunos ejemplos (cosa excepcional en el Diccionario de la R.A.E.): DICCIONARIO bibliográfico, biográfico, geográfico. Este artículo sobre el diccionario viene también a decirnos otra cosa: que lo que llamamos diccionario es un producto versátil y variado, fruto, sin duda, del carácter utilitario del mismo.

Es precisamente el carácter utilitario del diccionario el que ha dado lugar a la aparición de diccionarios muy diversos, desde el clásico diccionario de lengua (como puede ser el Diccionario de la R.A.E.) y los diccionarios enciclopédicos (las enciclopedias que todos tenemos en nuestras casas) a diccionarios de muy distinto tipo: diccionarios especializados (del deporte, de la caza, etc.), o bien los citados por la Real Academia Española, como diccionarios lato sensu: diccionario bibliográfico, biográfico, geográfico, etc.

Pero el carácter utilitario del diccionario no sólo se refleja en los distintos tipos de diccionario en lo que se refiere -podríamos decir- a su macroestructura, sino, sobre todo, a su microestructura.

Dentro de la Lexicografía práctica relativamente reciente han aparecido otros tipos de diccionarios, entre los que no es muy fácil distinguir claramente: son los diccionarios 'de uso', 'escolares' y 'de aprendizaje (de una lengua extranjera)' (los lear$n e r^{\prime}$ s dictionaries propiamente dichos). Han sido precisamente estos diccionarios los que han venido aportando mayores novedades lexicográficas.

Siguiendo a HAENSCH (1997: 150) señalaremos que lo que caracteriza a un 'diccionario de uso' es poseer al menos dos de las tres siguientes características:

a) Ampliación paradigmática: información sobre sinónimos, antónimos y familias de palabras. El diccionario tradicional lo daba, en su caso, en el empleo de sinónimos o antónimos en la definición.

b) Ampliación sintagmática: da razón del contexto, la llamada 'colocación' del lema, valencias verbales, etc. Es una información apenas existente el los diccionarios tradicionales del español, salvo al definir frases hechas y en las escasas ocasiones que aportaban ejemplos. 
c) Frases-ejemplo: Uno de los primeros diccionarios que ofrecía 'frases-ejemplo' en el ámbito del español- era el Larousse Júnior 1989. Pero es menester señalar de antemano que conviene tener muy claras estas tres nociones: la definición frase, la frase-ejemplo y el 'ejemplo' propiamente dicho.

Pero, además, consideramos que en la descripción de los diccionarios de aprendizaje ha de incluirse otro rasgo fundamental, que no debe estar ausente de la reflexión previa a la elaboración de cualquier diccionario:

d) La selección del vocabulario. En efecto, la creación de los vocabularios básicos o vocabularios fundamentales está en la base de la elaboración de los diccionarios de aprendizaje. Recordemos aquí el Français fondamental de Georges Gougenheim y, sobre todo, el BASIC (British American Scientific International Commercial) English, debido a Charles K. Ogden.

Por tanto, resumiendo, los aspectos novedosos que afectan a la elaboración de estos nuevos diccionarios son los siguientes:

$\left.1^{\circ}\right)$ La selección del vocabulario. Ciertamente, los tradicionales diccionarios generales de lengua (no así, los diccionarios específicos o de especialidad): los diccionarios académicos o los diccionarios generales de una lengua, no se planteaban propiamente la selección del vocabulario. En el fondo tenían vocación de 'exhaustividad'. La REAL ACADEMIA ESPAÑOLA (1970: s.v. lexicografía) definía así el término lexicografía: "Arte de componer léxicos o diccionarios, o sea de coleccionar todas las palabras [el subrayado es nuestro] de un idioma y descubrir y fijar el sentido y empleo de cada una de ellas". Obviamente, y de hecho, no se trataba de una exhaustividad absoluta, pero sí de una exhaustividad definida por la lengua -así considerada- correcta. En cierto modo lo que no aparecía en el Diccionario de la R.A.E. no era susceptible de ser usado correctamente, no tenía autoridad. Si una palabra no venía o viene en el Diccionario de la R.A.E., es como si no existiera como palabra digna de ser utilizada ${ }^{1}$.

En efecto, quizás el primer aspecto que conviene señalar como característico de los diccionarios de aprendizaje es el relativo a la selección del vocabulario. Ciertamente los diccionarios generales de la lengua son vistos por el usuario como thesaurus, como diccionarios integrales, y sus creadores los presentan como diccionarios en cierto modo completos, que van evolucionando por la adición de neologismos, integrados ya en la lengua general. El propio Diccionario de Autoridades se presenta así en el Prólogo: "El principal fin que tuvo la Real Academia Española para su formación fue hacer un Diccionario copioso y exacto" (Diccionario de Autoridades: I). Asimismo, la Real Academia Española se presenta como deudora del Tesoro de Covarrubias, al que pretende completar. Los siguientes diccionarios de la Real Academia (ya sin las autoridades), hasta su última edición, REAL ACADEMIA EsPAÑOLA 2001, van incorporando en sus ediciones con mejor o peor criterio los términos nuevos.

En la actualidad los nuevos diccionarios, que parten de corpus recogidos periódicamente en soporte informático, pueden manejar criterios objetivos de frecuencia, si bien suelen combinarlos con otros criterios que podemos llamar 'cualitativos'. Quizás el caso más conocido sea el del Collins COBUILD, que parte de un corpus de 20.000

\footnotetext{
${ }^{1}$ Observemos la validez del Diccionario de la R.A.E. para pruebas jurídicas, etc.
} 
millones de palabras, sobre el cual se han obtenido las más de 70.000 entradas del diccionario ${ }^{2}$.

$2^{\circ}$ ) La ampliación paradigmática. Otro aspecto muy relevante (porque salta a la vista y porque, por ello, acentúa o muestra abiertamente su carácter utilitario) es el de la 'ampliación paradigmática': sinónimos, antónimos, familias de palabras, que pueden aparecer en el cuerpo del artículo del diccionario (al final del artículo o tras cada una de las acepciones) o bien en columnas laterales del cuerpo del artículo (como en el Collins COBUILD o en el Robert des Jeunes). Prácticamente todos los diccionarios modernos, se etiqueten como se etiqueten: 'diccionarios generales', diccionarios 'de uso', 'escolares' o 'de aprendizaje (de una lengua extranjera)', incorporan estos tipos de informaciones.

$\left.3^{\circ}\right)$ La ampliación sintagmática. Con relación a la 'ampliación sintagmática', los diccionarios tradicionales -nos referimos señaladamente a las sucesivas ediciones del Diccionario de la R.A.E.- apenas incorporan ejemplos, salvo en pocos casos, que, por lo tanto, pueden calificarse de raros. He aquí algunos casos obtenidos al azar en DRAE-1992:

En la $10^{\mathrm{a}}$ acepción de hombre: "Unido con algunos sustantivos por medio de la prep. de, el que posee las cualidades o cosas significadas por tales sustantivos. HOMBRE de honor, de tesón, de valor".

En algunas de las acepciones de menos, por ejemplo, en la 2a: "Denota a veces limitación indeterminada de cantidad expresa. En esta importante batalla murieron MENOS de cien hombres; son MENOS de las diez".

En la definición de din, en la que, después de decir que es un uso familiar o hipocorístico de dinero, explica que se usa "en frases como las siguientes: El DIN y el don; el don sin el DIN; esto es, dinero y calidad; nobleza sin bienes de fortuna".

En cualquier caso el recurso a los ejemplos en el Diccionario de la RAE es muy escaso y así ocurre en otros muchos diccionarios 'tradicionales', entre los que se incluye también el DUE-MOLINER.

Como hemos señalado antes, los ejemplos vienen a dar razón de numerosas informaciones necesarias, siendo la más importante la que se refiere a la llamada 'colocación'. Con este término se hace referencia al 'entorno' sintagmático de la palabra. Ahora bien, la colocación tanto puede referirse a un entorno sintagmático gramatical (valencias verbales, etc.) como semántico (en un sentido más general, como el referido por los rasgos de clase: "animado" / "inanimado", "discreto" / "continuo", etc.; o bien, en un sentido más específico, como el relativo a la combinación de palabras como ladrido, barrito, etc.).

$\left.4^{\circ}\right)$ La definición lexicográfica. Sin embargo, y a pesar de que los puntos anteriores dan buena razón de aspectos que han incorporado los diccionarios 'modernos' (entre comillas), quizás la 'revolución' (también entre comillas) o revelación de los nuevos diccionarios sea el intento de modificar la definición.

\footnotetext{
${ }^{2}$ Un estudio sobre las características de los 'learner's dictionaries' propiamente dichos, en el ámbito del inglés, hace DODD (1994), que analiza para cada diccionario: $1^{\circ}$ ) Vocabulario: número de entradas y número de ejemplos. $2^{\circ}$ ) Índice de dibujos. $3^{\circ}$ ) Orden de cada entrada. $4^{\circ}$ ) Características tipográficas. $5^{\circ}$ ) Sistema de etiquetado: regionalismos, nivel del lenguaje, transcripción fonética. $6^{\circ}$ ) Sistema gramatical.
} 
Obviamente, el diccionario tiene por misión primaria dar el significado de las palabras y, de alguna manera, a la definición habrán de afectar las reformas lexicográficas. Tales reformas, en lo que respecta a la definición, se reducen a dos fundamentalmente:

a) La sustitución de la definición lexicográfica tradicional (realizada por medio de sinónimos o paráfrasis sinonímicas) por un ejemplo, la 'frase ejemplo'; así, compárese:

\begin{tabular}{||l|l||}
\hline esclavo, va. adj. Dícese & $\begin{array}{l}\text { esclavo, a } \text { s. Este hombre es } \\
\text { del hombre o la mujer } \\
\text { que por estar bajo el } \\
\text { domino del alcohol; está } \\
\text { de libertad. Ú.t.c.s. }\end{array}$ \\
rousse Júnior 1989). \\
\hline
\end{tabular}

b) La sustitución de la definición lexicográfica tradicional por la así llamada 'definición frase', que de alguna manera integra el lema en la definición y, por ello, resuelve algunos problemas de colocación, básicamente gramaticales:

\begin{tabular}{||l|l||}
\hline \hline $\begin{array}{l}\text { esclavo, va. adj. Dícese } \\
\text { del hombre o la mujer } \\
\text { que por estar bajo el } \\
\text { dominio de otro carece } \\
\text { de libertad. Ú.t.c.s. }\end{array}$ & $\begin{array}{l}\text { slave 1 A slave is 1.1 a per- } \\
\text { son who belongs to some- } \\
\text { one else as their property } \\
\text { and has to work for them. }\end{array}$ \\
EG ..a story about a slave who \\
escapes and becomes a free \\
man. (Collins COBUILD).
\end{tabular}

Como vemos, la 'definición frase' apenas modifica o altera la definición lexicográfica tradicional. Los mejores diccionarios escolares dejan a un lado la 'frase ejemplo' porque, como señala LEHMANN (1993: 202), “contrariamente a la mayoría de los diccionarios para niños que sacrifican la definición por juzgarla demasiado abstracta en beneficio de la frase-ejemplo (seguida de una definición o de una glosa) el $R J$ presenta, análogamente a los diccionarios para adultos, verdaderas definiciones". En efecto, como se señala en el 'Prefacio' del Robert des Jeunes, "hay frases-ejemplo que no permiten acceder al significado exacto de una palabra; esto sólo puede hacerlo la definición ya que ella generaliza, en tanto que el ejemplo particulariza" (Robert des Jeunes: X). Es decir, parece que el solo ejemplo no ayuda a fomentar la capacidad de abstracción que tiene que ir formando y desarrollando la inteligencia.

Por otra parte, observamos que la utilidad de estos diccionarios lleva a incorporar definiciones enciclopédicas. 
A su vez, las definiciones de estos nuevos diccionarios no rehuyen la redundancia en las definiciones. Más aún, tienden a cultivar la redundancia en sus informaciones ${ }^{3}$.

Los nuevos diccionarios 'de uso', 'escolares' o 'de aprendizaje' incorporan más elementos novedosos en aras de su utilidad y eficacia, como son: informaciones enciclopédicas, imágenes (en su caso) ${ }^{4}$, mayor información gramatical que los diccionarios tradicionales, informaciones fonéticas, ortográficas, etc., una mayor referencia de 'marcas', etc., etc. Precisamente de este otro conjunto de informaciones (señaladamente de la última citada) vamos a tratar propiamente en lo que sigue. Valga, pues, esta relativamente larga introducción para situar en su lugar el objeto propio de esta exposición, que desarrollamos a continuación.

Dentro de la Lexicografía tradicional, SECO (1977: 217-219) incluye todo este tipo de informaciones bajo la etiqueta de 'primer enunciado', porque, en su mayoría, van delante de la definición propiamente dicha. Vaya, de antemano, lo siguiente: los nuevos diccionarios pueden incluso incorporar parte de este conjunto de informaciones fuera de la columna central e ir en columnas laterales, como vemos en el Collins COBUILD o en el Robert des Jeunes. El DRAE-1992 incluye en el llamado por M. Seco 'primer enunciado' las siguientes informaciones ${ }^{5}$, como se ve, de muy diverso tipo; de forma análoga hace HAENSCH (1982: 482):

\begin{tabular}{|c|c|}
\hline DRAE-1992 & HAENSCH (1982: 482) \\
\hline $\begin{array}{l}\left.1^{\circ}\right) \text { Sobre la etimología u origen de la } \\
\text { palabra. }\end{array}$ & $\left.1^{\circ}\right)$ Indicaciones ortográficas. \\
\hline $2^{\circ}$ ) Sobre su categoría gramatical. & $2^{\circ}$ ) Indicaciones fonéticas. \\
\hline $\begin{array}{l}\left.3^{\circ}\right) \text { Sobre su ámbito dialectal o geo- } \\
\text { gráfico. }\end{array}$ & $\left.3^{\circ}\right)$ Indicaciones etimológicas. \\
\hline $\begin{array}{l}\left.4^{\circ}\right) \text { Epoca de vigencia de la palabra: } \\
\text { bajo la abreviatura ant. se "indica } \\
\text { que la voz o la acepción pertenece al } \\
\text { vocabulario de la Edad Media"; bajo } \\
\text { la abreviatura desus. "se pone a las } \\
\text { voces y acepciones que se usaron en } \\
\text { la Edad Moderna pero que hoy no se } \\
\text { emplean ya". }\end{array}$ & $\left.4^{\circ}\right)$ Indicaciones gramaticales. \\
\hline
\end{tabular}

\footnotetext{
${ }^{3}$ Obviamente este factor acentúa el volumen y peso físicos del diccionario escolar, componente práctico importante en el mismo.

${ }^{4}$ Como hemos señalado en la nota 2, el índice de dibujos es uno de los criterios de análisis manejado por DoDD 1994.

${ }^{5}$ Como señala SECO (1977: 219), “todos estos elementos más o menos dispares que constituyen el 'primer enunciado' de un artículo tienen como característica formal común la sumisión a una normalización muy rígida. Así, cada una de estas informaciones ocupa un lugar fijo en el artículo: la etimología ocupa el espacio inmediato a la palabra-entrada; el segundo está reservado a la categoría gramatical; el tercero corresponde a la vigencia cronológica, al ámbito geográfico, al ámbito de actividad o nivel social; por último, tras una ruptura de continuidad por la presencia de la definición -o 'segundo enunciado'-, se expone, cuando la hay, información complementaria, habitualmente de tipo gramatical".
} 
50) Campo del saber (antropología, botánica, matemáticas) o de la actividad (carpintería, deportes, imprenta).

$\left.6^{\circ}\right)$ Niveles de uso, a través de abreviaturas como fam., vulg., pop., poét., rúst.

$\left.7^{\circ}\right)$ Particularidades de 'colocación', por ejemplo: "Úsase en las anotaciones de impresos y manuscritos castellanos" (s.v. pássim); "en frases como las siguientes: El DIN y el don; el don sin el DIN; esto es, dinero y calidad; nobleza sin bienes de fortuna" (s.v. din).

$8^{\circ}$ ) Explicación de transiciones o desviaciones semánticas, por medio de abreviaturas como fig., por ext., irón. (en acepciones secundarias). $5^{\circ}$ ) Indicaciones cronológicas.

$6^{\circ}$ ) Indicaciones sobre niveles de estilo y connotaciones.

$7^{\circ}$ ) Indicaciones sobre la atribución a una materia o especialidad.

En relación con este tipo de indicaciones, generalmente expresadas por medio de abreviaturas, está la etiqueta y, consiguientemente, la noción de 'marca'. Se trata de una etiqueta o noción que se maneja con cierta frecuencia y que no ha sido sometida, al menos de manera suficiente, a una crítica: definición y delimitación de la misma ${ }^{6}$.

La noción de marca tiene su origen en el ámbito de la fonología y su puesta en cuestión fue instada epistolarmente por N.S. Trubetzkoy en 19307. Ulteriormente el problema se desplazó a la gramática y a otros ámbitos de la investigación lingüística8 . $^{2}$ Uno de estos ámbitos es la Lexicografía.

La noción de marca en Lexicografía se refiere a todo aquello que se separa del lenguaje 'normal' o 'común'. En efecto, como señalábamos en RODRíGUEZ DíEZ (1981: 43), cuando algo se considera marcado siempre se hace "con referencia o relación a un elemento no marcado, más general o extenso: la lengua o léxico común"9. Ahora bien, lo que denominamos marcado puede abarcar innúmeras dimensiones, como una rosa de los vientos de ilimitadas puntas, con la particularidad, en el caso que nos

\footnotetext{
${ }^{6}$ Diccionarios tradicionales de lingüística no hacen referencia a este término en su aplicación a la lexicografía; así, por ejemplo, el de G. Mounin o el de J. Dubois et al.

${ }^{7}$ Vid. JAKOBSON 1980/81: 98-103.

${ }^{8}$ De forma análoga -y al socaire- a lo que ocurrió con la noción de 'neutralización', también surgida en el ámbito de la fonología. Recuérdese la conocida encuesta formulada por A. Martinet en 1956 (MARTINET 1957). Vid. nuestro trabajo, RODRíGUEZ DíEz 1997.

${ }^{9}$ Introducimos aquí explícitamente el término léxico no por entender que la oposición 'común' / 'no-común' se refleje exclusivamente en el léxico. Evidentemente no es así, como ya hemos señalado. Sin embargo, dejadas a un lado las diferencias dialectales, en los demás casos los rasgos 'no-comunes' se reflejan mayoritariamente en el léxico, en defecto de la escasa diferenciación fonológica y morfológica, por un lado, y de las poco estudiadas diferencias sintácticas. Explícitamente lo señala COSERIU (1967/77: 119): "Las diferencias correspondientes a los tres tipos [diferencias diatópicas, diferencias diastráticas y diferencias diafásicas] se registran en la fonología, en la gramática y también en el léxico; y hasta se podría decir, sobre todo en el léxico".
} 
ocupa, de que tales dimensiones no son precisamente homogéneas. Obsérvese el siguiente esquema:

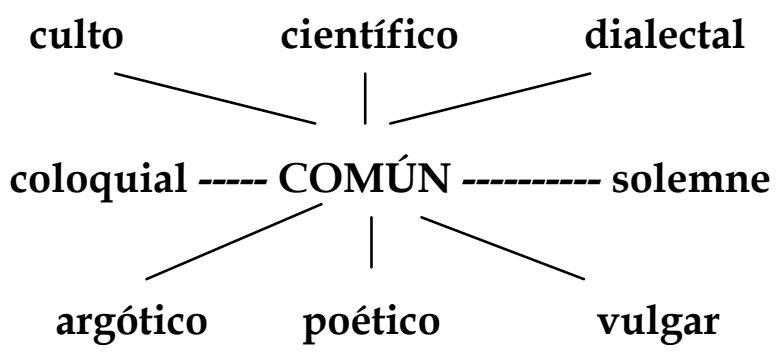

Como consecuencia de esta situación, la lingüística tradicional distinguía en una lengua o idioma dialectos, niveles de lengua y estilos de lengua ${ }^{10}$, lo que L. Flydal denominaba arquitectura de la lengua ${ }^{11}$. Por su parte, E. Coseriu, a fin de distinguir la 'lengua real', que es variable y que constituye una 'arquitectura', de la 'lengua objeto de un estudio estructural', que es uniforme, adopta la distinción de lengua histórica y lengua funcional, señalando en aquélla, la lengua histórica, las siguientes variedades o diferencias: diferencias diatópicas (los tradicionales dialectos), diferencias diastráticas (los tradicionales niveles de lengua) y las diferencias diafásicas (los tradicionales estilos de len$g u a)^{12}$, quedando éstas últimas como un auténtico 'cajón de sastre', en el que se apilan varias distinciones en variados ejes heterogéneos, quedando fuera otros, de notable importancia en la investigación lingüística, como las lenguas especiales, lo que hemos tenido ocasión de señalar ${ }^{13}$.

Volviendo a la noción de 'marca' o de lo 'marcado', no queda más remedio que señalar que siempre se puede identificar algo como marcado, con relación a lo así denominado 'común'. De todo esto se puede deducir que "la lengua o léxico común es indefinible por sus propiedades específicas positivas y, de alguna manera también, inasible como objeto real. Es un producto mental por exigencias de la teoría [...]. En resumen, la noción de lengua o léxico común es fruto de una necesidad metodológica, la de señalar, en cada una de las dimensiones en que se puede abordar el estudio del habla real, la presencia de ciertos elementos o rasgos que se consideran marcados con relación a los demás de una lengua dada que no lo están en la oposición"14.

En el caso que nos ocupa estas afirmaciones van referidas al léxico, pero son válidas para cualquier plano del análisis lingüístico. De ahí que J. Rey-Devobe -en el contexto o ámbito de la Lexicografía- llegue a la siguiente conclusión: "Parece así que el concepto de lengua común (en la mayor parte de los casos) se mezcla con el de

\footnotetext{
${ }^{10}$ En este contexto también aparecía la noción de registro, englobadora prácticamente de todas las demás, señaladamente de las dos últimas (vid. GARRIGA).

${ }^{11}$ El término arquitectura de la lengua, para designar "el conjunto de relaciones que implica la multiplicidad de las 'técnicas del discurso' coexistentes en una lengua histórica (es decir, al conjunto de las relaciones entre los 'dialectos', los 'niveles' y los 'estilos de lengua' que constituyen la lengua histórica)", lo toma prestado CosERIU (1967/77: 120) de FLYDAL 1951.

12 "Una 'técnica del discurso' homogénea desde estos tres puntos de vista, es decir, una técnica considerada en un solo punto del espacio, en un solo 'nivel de lengua' y en un solo 'estilo de lengua' (técnica sintópica, sinstrática y sinfásica) se llamará a continuación lengua funcional”. (COSERIU 1967/77: 119).

${ }^{13}$ Vid. nuestro trabajo, RoDRíGUEZ DíEz 1981: 41-52.

${ }^{14}$ Rodríguez DíEz 1981: 45.
} 
lengua opuesto a discurso"15. Ahora bien, -como señalábamos en otro lugar- la gran utilidad de los planteamientos señalados de E. Coseriu “como perspectiva metodológica para aislar la lengua funcional, no resuelve los problemas prácticos de identificación de muchos fenómenos lingüísticos como tales"16, que es lo que pretende la Lexicografía al señalar en los diccionarios determinadas unidades como marcadas en una determinada dimensión. En efecto, lo 'común' o lo 'funcional' está definido negativamente, como 'aquello de lo que no se habla en el momento', tal como señalábamos arriba. Por el contrario, lo 'marcado' ha de ser identificado positivamente.

Ahora bien, ¿cuántas son las dimensiones o ejes -las variedades lingüísticas- susceptibles de ser distinguidos en una lengua histórica? Por otra parte, ¿cuántas de esas dimensiones conviene introducir o señalar -'marcar' - en el léxico, en concreto, en un diccionario? A su vez, si a esas indicaciones o rasgos les llamamos 'marcas', ¿cuál es la tipología de las marcas de un diccionario?

En la práctica lexicográfica la noción de marca está ligada frecuentemente a etiquetas del tipo 'vulgar', 'despectivo', 'irónico', etc., etc., de ahí que frecuentemente se hable de 'marcas de uso'17, viniendo a englobar lo que podríamos denominar, siguiendo a E. Coseriu, variantes o 'diferencias diafásicas', frente a las 'diferencias diatópicas' y a las 'diferencias diastráticas', más concretas y definidas en la tradición académica ${ }^{18}$. No obstante, a veces la etiqueta de 'marca' se aplica a todas o buena parte de las indicaciones que comportan lo que SECO (1977) denomina o incluye en el 'primer enunciado'. La Lexicografía práctica y, sobre todo, la teórica, resumida tradicionalmente ésta última en los prólogos de los diccionarios, no hacía mayores clasificaciones, limitándose a añadir o reducir el número de las marcas en función del buen saber y entender del redactor del diccionario. Incluso había que rastrear las referidas marcas en la maraña del listado de abreviaturas que introducía el diccionario. Es decir, que tampoco los teóricos de la Lexicografía van mucho más allá de la enumeración de los hechos que aparecen en los diccionarios, y no se plantean de antemano cuántas y cuáles han de ser las así llamadas 'marcas' de un diccionario. Quizá vengan bien aquí a este propósito, una vez más, las conocidas palabras de WEINREICH (1967: 26) en una crítica muy dura y no muy justa: "La indiferencia que muestra la lexicografía hacia su propia metodología es asombrosa. Quizá están satisfechos los lexicógrafos porque su producto 'funciona'. Pero es legítimo preguntarse de qué manera funciona que no sea la de que los diccionarios se venden".

Dentro de la Lexicografía teórica, el breve, pero muy interesante, artículo de HAUSSMANN (1989: 649-657) es uno de los primeros en plantearse expresamente una descripción y tipificación de las marcas en los diccionarios generales de lengua. Bien es cierto que el manejo de la noción o etiqueta de 'marca' -o 'marcación', como denomina HAENSCH (1982: 138)- es relativamente reciente ${ }^{19}$ y se hace al socaire de la identificación de los diversos tipos de obras lexicográficas (en una palabra, de distintos diccionarios).

\footnotetext{
${ }^{15}$ Rey-Devobe 1971: 67. Cfr. también LaGane 1969: 6-11.

${ }^{16}$ RODRÍGUEZ DíEz 1981: 43.

${ }^{17}$ Cf, por ejemplo, los trabajos de Garriga 1997, 1994-95, 1996, 1994 y 1999.

${ }^{18}$ Vid. COSERIU 1967-77.

${ }^{19}$ Vid. HAUSSMANN (1989: 649).
} 
En el referido artículo, F.J. Haussmann llega a identificar las once siguientes ${ }^{20}$ :

$1^{\mathrm{a}}$. Marca diacrónica (actual / viejo-nuevo).

2. Marca diatópica (común / regional-dialectal).

$3^{\mathrm{a}}$. Marca diaintegrativa (nacional / propio-extranjero).

$4^{\mathrm{a}}$. Marca diamedial (neutro / hablado-escrito).

5a. Marca diastrática (neutro / alto nivel-bajo nivel; infantil-esco-lar).

$6^{\mathrm{a}}$. Marca diafásica (neutro / formal-informal).

$7^{\mathrm{a}}$. Marca diatextual (neutro / poético-literario-periodístico-admi-nistrativo...).

$8^{a}$. Marca diatécnica (común / especial).

9a. Marca diafrecuente (frecuente / raro).

$10^{a}$. Marca diaevaluativa (diaconnotativa) (neutro / connotativo) ('derogado', eufemístico)

$11^{\text {a }}$. Marca dianormativa (correcto / incorrecto).

Curiosamente, en el volumen que presenta HAUSSMANN (1989) se realiza el tratamiento específico de cada una de las 'marcas' en ocho capítulos o artículos concretos que las desarrollan, pues el análisis de las marcas de la $4^{\mathrm{a}}$ a la $7^{\mathrm{a}}$ se hace en un solo capítulo o artículo ${ }^{21}$. Esta clasificación de marcas no deja de ser fruto de una mera lectura o mirada, más o menos panorámica o superficial, de los diccionarios que son fuente de estos trabajos. La tipología de 'marcas' que se propone muestra el carácter pragmático o utilitario, ad hoc, de esta clasificación que, como señalamos, presenta en esquema F.J. Haussmann en el artículo, introductor a los específicos de cada tipo de marca, titulado Die Markierung im allgemeinen eisnsprachigen Wörterbuch: eine Übersicht.

Ahora bien, una primera cuestión que se puede siempre plantear es si la tipología de las marcas se agota en las once que se muestran. Más aún, habría que analizar si las oposiciones que las identifican son binarias o ternarias, etc.; privativas o polares; o bien comportan una tipología interna abierta en cuanto al número, como, por ejemplo es el caso de los distintos tipos de especialidad o actividad que subyacen bajo la marca 'diatécnica'. Obviamente, el carácter meramente constatador de los hechos no es suficiente para validar una clasificación. Se echa en falta, pues, en esta clasificación un aparato teórico que justifique los distintos ejes -y su naturaleza- por medio de los cuales convenga 'marcar', o a los cuales convenga asignar, ciertas palabras o usos. Las limitaciones y restricciones a una tipología de las 'marcas' no sólo vendrán exigidas por la lógica de los planteamientos teóricos, sino -como es habitual en la Lexicografía- por la utilidad del producto, el diccionario. Sin embargo, ambas exigencias, la teórica y la pragmática, no deben entrar en contradicción.

A pesar de las observaciones críticas que se pueden hacer al tratamiento que sobre las marcas se hace en HAUSSMANN (1989), hay que reconocer que estamos ante un

\footnotetext{
${ }^{20} \mathrm{Vid}$. el esquema o modelo general de las marcas del diccionario en HAUSSMANN (1989: 651).

${ }^{21}$ He aquí los autores y títulos de los diferentes capítulos o artículos: SCHMIDT 1989 (marca diacrónica), NiEBAUM 1989 (marca diatópica), CARSTENSEN 1989 (marca diaintegrativa), CORBIN 1989 (marcas diamedial, diastrática, diafásica y diatextual), KALVERKÄMPER 1989 (marca diatécnica), SCHAEDER 1989 (marca diafrecuente), PÜSCHEL 1989 (marca diaevaluativa), GLATIGNY 1989 (marca dianormativa).
} 
tratamiento riguroso de este problema, tan importante para la Metalexicografía. El mero hecho de haberse planteado, tal como se hace, supone un interesante avance en esta disciplina.

Sin embargo, si la noción de marca acusa deficiencias -obvias- en sus planteamientos teóricos, su aplicación en la práctica lexicográfica resulta aún muy endeble, errática y poco crítica. Así, por ejemplo, HAENSCH (1982) no hace referencia expresamente a la noción de marca, sino que menciona varias de las señaladas arriba al socaire del desarrollo de los capítulos 3 y 9, titulados, respectivamente, “Tipología de las obras lexicográficas" y "Aspectos prácticos de la elaboración de diccionarios" 22 . Por su parte $D R A E-1992$ no hace referencia a las 'marcas' salvo en la edición electrónica, DRAE-1992/95, donde habla de 'Índice de abreviaturas y marcas'23.

Curiosamente, el referido 'Índice de abreviaturas y marcas' del DRAE-1992/95 supone toda una reflexión sobre lo que son las marcas de un diccionario o, dicho de otra manera, lo que es menester 'marcar' a la hora de elaborar el artículo de un diccionario. La exigencia, por parte de los autores y, sobre todo, de los supervisores del Instituto de Lexicografía de la Real Academia Española, de facilitar de la mejor manera posible el acceso a los contenidos del DRAE-1992 desde las peculiaridades del soporte informático les ha llevado a organizar de alguna manera -en este caso utilizando un modelo arborescente- el conjunto heterogéneo de abreviaturas que aparecen en la parte introductoria del diccionario y, además, a extraer del propio cuerpo de la definición distintos rasgos, objetivables como 'marcas', en parte coincidentes, pero, en parte, añadidas a las incorporadas con las abreviaturas correspondientes. Dicho de otra manera -y en los términos de SECO (1977)-, se trata de ordenar las indicaciones que forman parte del $1{ }^{\mathrm{er}}$ enunciado y también aquéllas otras referencias análogas que se deslizan dentro del $2^{\circ}$ enunciado, la definición propiamente dicha.

Hay que tener en cuenta que, en el caso de la versión electrónica del DRAE1992/95, la enumeración o tipificación de las 'abreviaturas y marcas' está al servicio del manejo electrónico del diccionario. Es decir, los autores de la versión electrónica no se plantean hacer -o cómo hacer- un diccionario, sino cómo aprovechar electrónicamente un concreto diccionario semasiológico, es decir, alfabético: el DRAE-1992.

El resultado de esa ordenación de materiales da lugar al 'Índice de abreviaturas y marcas', cuya tipología incluye los siguientes 'árboles'24:

- Árbol de lenguas. Se refiere a las lenguas originarias, etimológicas, generalmente señaladas en el apartado de la Etimología, con alrededor de 300 referencias a lenguas o dialectos.

- Árbol de categoría gramatical.

\footnotetext{
${ }^{22}$ En total menciona las siguientes: marcación diacrónica (que en el cap. 9 recibe el nombre de 'cronológica'), marcación, diafásica, marcación diafrecuente, marcación diaintegrativa, marcación dianormativa, marcación diasistemática (poco definida), marcación diastrática, marcación diatécnica y marcación diatópica.

${ }^{23}$ Ya hemos mencionado anteriormente un listado de 8 indicaciones del DRAE-1992 -que podemos considerar 'marcas'- y que se pueden incluir en lo que M. Seco denomina $1^{\text {er }}$ enunciado.

${ }^{24}$ En los casos que consideramos interesantes incluimos entre paréntesis el número de ocurrencias. Tanto, a veces, su amplio número, como, otras, su número escasísimo (en casos, reducido a la unidad) dan razón del carácter exhaustivo de la descripción, así como de otras indicaciones de interés. Todo ello unido al rasgo general del diccionario académico: obra de aluvión quitando y poniendo, sin mayor unificación de criterios- a lo largo de los siglos.
} 
- Árbol de usos: ámbito geográfico. Se refiere a los ámbitos geográficos, dialectales, dentro del dominio del español, con alrededor de 170 referencias, la mayoría de las cuales ocupan el lugar del 1er enunciado y sólo algunas van dentro de la definición.

- Árbol de usos: materia o nivel:

a) Profesiones y disciplinas. Con más de 170 referencias, la mayoría de las cuales se indican con abreviaturas en el dominio del $1^{\mathrm{er}}$ enunciado.

b) Variantes socialmente marcadas. Se incluyen ocho referencias, heterogéneas tanto en sí como en el lugar y forma de indicación: caló (generalmente en el lugar de la etimología), dialectal (abrev. dialect., y en la definición: dialectal [3 ocurrencias], regional [1 oc.]), estudiantil (dentro de la definición, sin abreviatura), germanía (Ger.), infantil (dentro de la definición [7 oc.]), sin abreviatura), jergal (en la definición y en casos referido por lenguaje de la droga [3 oc.]), jerga orillera [1 oc.]), nombre vulgar (dentro de la definición, sin abreviatura [21 oc.]: nombre vulgar [20 oc.], designación vulgar [1 oc.]), rural o rústico (abrev. rur. [49 oc.], rust. [1 oc.], yendo en algunos casos dentro de la definición [18 oc.]: rural, rústico, gente del pueblo, campesinos, aldeanos).

c) Variantes desprestigiadas. Cuatro: grosero (dentro de la definición [1 oc.]), malsonante (al final de la definición, sin abreviatura [7 oc.]), vulgar (vulg. [232 oc.], Ú. c. vulg. [3 oc.], [uso, lenguaje, tratamiento] vulgar, vulgarmente, vulgarismo [31 oc.]), popular (pop. [14 oc.], [uso, lengua, tratamiento, ambiente, etimología, etc.] popular, popularmente, popularizado [15 oc.]).

- Árbol de opciones avanzadas. En este trabajo sobre de las 'marcas' nos interesan las que aparecen bajo la etiqueta de 'Usos: restantes' 25 , bajo la cual se incluyen dos apartados:

a) Tiempo: con las abreviaturas: ant. (en un caso ants.) "anticuado o antiguo", desus. "desusado", p. us. "poco usado" y dentro de la definición neologismo (una sola vez).

b) Intención: se trata de 'marcas' extraídas por los autores que elaboraron la versión electrónica de las definiciones; sin embargo, como señalamos expresamente, hay otros casos en que hay abreviaturas propias de la tradición lexicográfica de la Real Academia Española. La lista de estas marcas, 23, es la siguiente, junto con sus variantes:

\begin{tabular}{|l|l|l|}
\hline Etiqueta & $\mathbf{N}^{\mathbf{0}}$ ocurrencias & Referencias \\
\hline admirativo & 32 & "admiración", “admirativo" \\
\hline afectuoso & 26 & $\begin{array}{l}\text { "afecto, afectuoso, afectivo, } \\
\text { afectuosamente", "cariño, cari- } \\
\text { noso" }\end{array}$ \\
\hline amenazador & 24 & "amenaza" \\
\hline
\end{tabular}

\footnotetext{
${ }^{25}$ Además se añaden: 'Cuestiones etimológicas', 'Formación de palabras', 'Construcción y régimen', 'Cuestiones semánticas', con sus correspondientes subdivisiones internas, que no abordamos aquí.
} 


\begin{tabular}{|c|c|c|}
\hline burlesco & 14 & $\begin{array}{l}\text { "burla, burlesco, burlar(se), } \\
\text { burlescamente" }\end{array}$ \\
\hline coloquial & $34+1$ & coloq. + "coloquial" \\
\hline cortés & 25 & "cortesía, cortés, cortésmente" \\
\hline despectivo & $330249+16+65)$ & $\begin{array}{l}\text { despect. + otras abreviaturas }{ }^{26}+ \\
\text { "despectivo, despectivamente, } \\
\text { desprecio" }\end{array}$ \\
\hline no despectivo & 1 & no es despect. \\
\hline elevado & 1 & "elevado" \\
\hline enfático & 17 & énfasis, enfático, enfáticamente \\
\hline familiar & $10593(10519+43+31)$ & $\begin{array}{l}\text { fam. + fams. + "familiar, fami- } \\
\text { liarmente, estilo familiar" }\end{array}$ \\
\hline festivo & $50(43+7)$ & fest. + "festivo, festivamente" \\
\hline figurado & $\begin{array}{l}17431(17161+37+222 \\
+11)\end{array}$ & $\begin{array}{l}\text { fig. + figs. + otras abreviatu- } \\
\text { ras }^{27}+\text { figurado, figuradamente }\end{array}$ \\
\hline hiperbólico & 22 & $\begin{array}{l}\text { "exageración, exagerar, exage- } \\
\text { rativo, hiperbólico, hiperbóli- } \\
\text { camente" }\end{array}$ \\
\hline injurioso & 7 & $\begin{array}{l}\text { insulto, denuesto, injurioso } \\
\text { (especificadas como tales en la } \\
\text { p.) }\end{array}$ \\
\hline irónico & $125(61+17+47)$ & $\begin{array}{l}\text { irón. + otras abreviaturas }{ }^{28}+ \\
\text { "irónico, irónicamente, ironía" }\end{array}$ \\
\hline jocoso & 13 & $\begin{array}{l}\text { "humorístico" ("humorística- } \\
\text { mente, humor"), "jocoso" ("jo- } \\
\text { cosamente") }\end{array}$ \\
\hline juramento & 23 & $\begin{array}{l}\text { "fórmula de juramento, jura- } \\
\text { mento" }\end{array}$ \\
\hline literario & 5 & (lengua, lenguaje, uso) literario \\
\hline peyorativo & $68(5+5+40+18)$ & $\begin{array}{l}\text { Ú. m. en sent. peyorativo + otras } \\
\text { abreviaturas } 29+\text { " (sentido va- } \\
\text { lor, carácter) peyorativo, peyo- } \\
\text { rativamente" + "Úsase más en } \\
\text { sentido peyorativo" } 30\end{array}$ \\
\hline poético & $269(225+44)$ & poét. + "poético31, poesía32" \\
\hline ponderativo & $68(2+2+64)$ & $\begin{array}{l}\text { sent. ponderativo }+ \text { fr. ponderati- } \\
v a+\text { "ponderativo, pondera- }\end{array}$ \\
\hline
\end{tabular}

\footnotetext{
${ }^{26}$ Ú. t. c. despect. (2), Ú. m. en sent. despect. (4), Ú. m. c. despect. (2), Ú. t. en sent. despect. (4), Ú. en sent. despect. (3), Ú. c. despect. (1).

${ }^{27}$ Sent. fig. (7), Ú. en sent. fig. (7), Ú. t. en sent. fig. (198), Ú. m. en sent. fig. (9), Ú. m. en frs. figuradas (1).

${ }^{28}$ Sent. iron. (9), Ú. en sent. irón. (1), Ú. t. en sent. irón. (4), Ú. m. en sent. irón. (3).

${ }^{29}$ Sent. peyorativo (3), Ú. t. en sent. peyorativo (1), Ú. en sent. peyorativo (1)

${ }^{30}$ Con distintas redacciones, p. ej.: "se usa generalmente en sentido peyorativo", "suele tener sentido peyorativo", "se usa muy a menudo con matiz peyorativo", "suele usarse en sentido peyorativo", "se usa también en sentido peyorativo", "generalmente se usa con sentido peyorativo", "se usa con frecuencia en sentido peyorativo", etc.

${ }^{31}$ A veces: Ú. m. en lenguaje poético. Ú. en el lenguaje poético

${ }^{32}$ Ú. m. en poesía. Ya solo se usa en poesía. Ú. generalmente en poesía. Ú. solo en poesía. Ú. aún en poesía. Suele usarse aún en poesía. Ú. en poesía. Ú. frecuentemente en poesía.
} 


\begin{tabular}{|l|l|l|}
\hline & & ción, ponderar" \\
\hline saludo & 33 & $\begin{array}{l}\text { "(fórmula de) saludo, saluta- } \\
\text { ción, saludar, (fórmula de) } \\
\text { despedida, despedir(se), (ex- } \\
\text { presión de) bienvenida" }\end{array}$ \\
\hline
\end{tabular}

¿Cómo interpretar esto? Como justificación del gran número de marcas, de la heterogeneidad de las mismas y, en cierto modo (incluso en los casos en que se podría exigir una mayor restricción o concreción-, del carácter abierto de las distinciones está la capacidad del soporte informático, que permite un fácil acceso, además de un relativamente fácil manejo, a diferencia de lo voluminoso de un diccionario alfabético que puede ser de fácil manejo, pero muy pesado, incluso físicamente hablando. Un fenómeno aparte constituye la forma de acceso al diccionario en soporte informático, que supone un cambio cualitativo.

No obstante, hay que tener en cuenta -a la vista del referido árbol de abreviaturas del DRAE-1992/95, en el que incluso hay 'marcas' con una sola ocurrencia- que el árbol o clasificación de las marcas se puede mejorar, aunque sólo sea por vía de la reducción o simplificación, sin entrar en la congruencia interna de las distinciones o divisiones. En el caso que nos ocupa la necesidad de reflejar, sic et simpliciter, el diccionario alfabético en su redacción ha llevado a esa prolijidad exagerada.

De alguna manera los autores de la versión electrónica del DRAE-1992 tratan de aprovechar la eficacia del soporte informático para superar por medio del 'Árbol de abreviaturas y marcas' las limitaciones en este terreno del diccionario semasiológico tradicional. A fin de cuentas cabe interpretar el referido árbol como un esquema conceptual (de determinados conceptos, que llamamos 'marcas'), que se puede interpretar como en un diccionario onomasiológico en el que estuviesen fundidas las dos grandes partes del DILE-CASARES: la analógica y la alfabética. Podría quizás afirmarse que en la confección de los referidos índices de abreviaturas y marcas para su acceso informático se ha vuelto a planteamientos típicos del diccionario onomasiológico, bien que en el caso que nos ocupa, el DRAE-1992/95 de forma vicaria del DRAE1992, semasiológico y, por tanto, alfabético.

La pregunta que podríamos formularnos a estas alturas de la exposición es la siguiente: ¿Cómo ha reaccionado la Lexicografía editorial -léase los modernos diccionarios semasiológicos: 'de uso', 'escolares' y 'de aprendizaje (de una lengua extranjera)'33- ante esta situación?

Hemos tomado como referencia para hacer una pequeña muestra los diccionarios SM-Clave, Alcalá-VOX y SALAMANCA-Santillana, relativamente nuevos y novedosos, pues sus directores y redactores son conscientes de su finalidad y de las virtualidades lexicográficas que han de incorporar. Estos tres diccionarios aportan ciertas novedades con relación a los diccionarios de uso tradicionales, que podemos representar por el ya tradicional DUE-MOLINER, y las varias ediciones del Diccionario de la R.A.E. Entre estas 'novedades' están las que hemos señalado para la determinación

\footnotetext{
${ }^{33}$ Obsérvese que actualmente es muy notable la actividad editorial en la línea de ofrecer diccionarios escolares y de aprendizaje. Si bien el móvil inicial puede estar en necesidades pedagógicas e intereses comerciales, en un segundo momento surgen para editoriales y redactores las exigencias lexicográficas.
} 
de las características de los learner's dictionaries y análogos en las líneas precedentes. Más aún, en buena medida las presentan explícitamente en la parte introductoria y en los esquemas de manejo del diccionario que proponen.

En efecto, las exigencias prácticas -pedagógicas, por imperativo de la enseñanza del español como lengua materna o como lengua extranjera- han llevado a estos diccionarios, que hemos tomado como referencia, a insistir en aspectos varios, anejos a las informaciones tradicionales que constituían lo que SECO (1977) incluyó en el 1er enunciado y que han venido a denominarse genéricamente 'marcas'. Estos diccionarios incorporan novedosas informaciones gramaticales: (régimen de verbos y adjetivos, usos de ser y estar, etc.); fonético-fonológicas: indicaciones ortográficas y de pronunciación (incluso transcripción fonético-fonológica el Alcalá-VOX); semánticas, etc. más allá de las habituales informaciones paradigmáticas y sintagmáticas; incluso pueden incorporar informaciones enciclopédicas.

Sin duda alguna estos tres diccionarios que mencionamos forman parte de los primeros modelos de 'diccionarios de aprendizaje', tanto para usuarios españoles como extranjeros. Sin entrar en un juicio de cómo resuelven la incorporación de estas nuevas informaciones, ni del número e importancia de las que cada uno de ellos incorpora, nuestra labor aquí pretende fijarse en lo que se refiere a las 'marcas', en los términos que aquí se entiende esta noción, que también se denomina, como hemos señalado, 'marcas de uso'.

Curiosamente el diccionario SM-Clave concreta en su introducción este capítulo, bajo el epígrafe de 'Registro de uso': “Los valores anticuado (ant.), coloquial (col.), eufemístico(euf.), poético (poét.), vulgar (vulg.) y vulgar malsonante (vulg. malson.) aparecen en aquellas acepciones cuyo registro de uso es restringido" 34 .

Por su parte, el diccionario Alcalá-VOX, en lo que se refiere al conjunto de marcas que aquí nos interesan, incluye en la lista de abreviaturas (pues no hace referencia a ello en la introducción) las siguientes, como así se destaca por la tipografía: desp. 'despectivo', fam. 'familiar', fig. 'figurado', form. 'formal', hum. 'humorístico', p. ext. 'por extensión', vulg. 'vulgar'. A éstas marcas hay que añadir las propias de la especialidad ${ }^{35}$.

Únicamente el diccionario SALAMANCA-Santillana se refiere explícitamente en su 'Introducción' a las 'marcas'. Señala cuatro tipos de marcas (SALAMANCASantillana: IX) ${ }^{36}$ :

a) Tecnicismos (AER. “aeronáutica”, etc., hasta 80 marcas)

b) Marcas de uso o registro (9 marcas: restringido, rural, vulgar, jergal, coloquial, literario, elevado, administrativo, afectado), además del normal o neutro, que no se señala.

\footnotetext{
${ }^{34}$ Expresamente señala que se prescinde de la tradicional marca de figurado (fig.) "porque esa información sólo adquiere pleno sentido cuando las acepciones están ordenadas por un criterio etimológico (y no de uso, como es el caso de este diccionario Clave" (SM-Clave: XVI).

${ }^{35}$ Del tipo de las siguientes: Aeronáutica, Agricultura, Anatomía, Arqueología, Arquitectura, etc., hasta un total de treinta y nueve.

${ }^{36}$ Hay que destacar que el término marca lo emplea el diccionario SALAMANCA-Santillana, como se ve, en un sentido más amplio, ya que introduce bajo esta etiqueta los 'tecnicismos' y unas concretas variantes dialectales, los 'hispanoamericanismos'. Sólo las mencionadas en los apartados a) y b) se ajustan bien al sentido más estricto o restringido del término 'marca'.
} 
c) Marcas de pragmática (23 marcas):

$\begin{array}{ccc}\text { amenaza } & \text { afectivo } & \text { afirmación } \\ \text { ánimo } & \text { anticipador narrativo } & \text { contestación a presentación } \\ \text { despedida } & \text { disgusto y enfado } & \text { eufemismo } \\ \text { humorístico } & \text { infantil } & \text { insulto } \\ \text { intensificador } & \text { ironía } & \text { llamada de atención } \\ \text { negación } & \text { petición } & \text { peyorativo } \\ \text { presentación } & \text { resumidor final } & \text { saludo } \\ \text { sorpresa } & \text { tratamiento } & \end{array}$

d) Hispanoamericanismos (el resto de términos dialectales del español se agrupan bajo la genérica etiqueta de 'uso restringido', dentro del apartado b/ 'marcas de uso o registro').

A la vista de este breve panorama podemos señalar que, de hecho, estos nuevos diccionarios -bien que más breves por lo utilitarios- no superan ni en cuanto a los distintos tipos de marcas ni en cuanto a su diversidad interna el aparato de informaciones que genéricamente se puede denominar 'marcas' y que incorporaba la lexicografía tradicional, representada entre nosotros por los Diccionarios de la R.A.E., el DUEMOLINER, etc. En su favor se encuentra la conciencia expresa de la necesidad de las mismas en función de los usuarios. Incluso, uno de ellos, el SALAMANCA-Santillana, en lo que se refiere a las marcas, así llamadas, pragmáticas desarrolla una tipología relativamente amplia (23 marcas).

Como conclusión podemos advertir que los nuevos diccionarios 'escolares', de 'uso' o 'de aprendizaje' no aportan, de hecho, grandes novedades en lo que se refiere a la incorporación de 'marcas de uso', ni, por lo general, en lo que se refiere al resto de las así llamadas, genéricamente, 'marcas'. Este déficit es tanto teórico (falta de supuestos metodológicos que permitan disponer de una tipología adecuada) como práctico (forma de incorporar las marcas en el diccionario semasiológico, alfabético). La edición electrónica del DRAE-1992/95 ha venido a constatar que el tradicional Diccionario de la R.A.E. incorporaba numerosas informaciones propias de las 'marcas de uso' y de las 'marcas' en general, bien que la propia ordenación del diccionario, semasiológico, no permitiera tener conciencia de su amplitud ${ }^{37}$.

Otra conclusión que podemos obtener de este repaso por los diccionarios académicos y de uso tradicionales y los más modernos de uso, escolares o de aprendizaje de una lengua extranjera es que las deficiencias de tales diccionarios, en principio atribuibles a las exigencias de una limitada amplitud y, en su caso, a la falta de una metalexicografía suficientemente desarrollada, pueden deberse también, en buena medida, a las limitaciones estructurales del diccionario semasiológico, alfabético. Quizás en un futuro próximo algunas de estas dificultades se puedan subsanar, en concreto en lo referido a las 'marcas', a través de los diccionarios en soporte informático. Se trataría de productos lexicográficos pensados para este soporte, que de alguna manera vendría a suponer la superación de la tajante diferencia entre los dicciona-

\footnotetext{
${ }^{37}$ Ciertamente el carácter tradicional -y en cierto modo, de aluvión- que tienen los Diccionarios de la R.A.E. ha impedido una toma de conciencia -y por tanto, una ausencia de aplicación- de los problemas y necesidades de un diccionario de uso. A ello puede haber contribuido el carácter en parte integral y normativo que tienen los Diccionarios académicos.
} 
rios onomasiológicos, sistemáticos, y los diccionarios semasiológicos, alfabéticos, presentados ambos con formato libro. Quizás así se podrían llevar a buen puerto las ideas que alumbraron el magnífico proyecto de J. Casares y que dio lugar al DILE-CASARES, lastrado por las limitaciones del soporte de papel ${ }^{38}$.

\section{REFERENCIAS BIBLIOGRÁFICAS}

CARSTENSEN, B. (1989), “Die Markierung von Entlehnungen im allgemeinen einsprachigen Wörterbuch", en HAUSSMANN, F.J. et al. (eds.), Wörterbücher. Dictionaries. Dictionnaires. Ein Internationales Handbuch zur Lexikographie I, Berlin-New York (W. de Gruyter), pp.668-672.

CONSEIL DE LA COOPÉRATION CULTURELLE DU CONSEIL DE L'EUROPE (1967), Les théories linguistiques et leurs applications (Actes du premier colloque international de linguistique appliquée, Nancy, 26 al 31 de octubre 1964, Nancy: AIDELA.

CORBIN, P. (1989), "Les marques stylistiques/diastratiques dans le dictionnaire monolingue", en HAUSSMANN, F.J. et al. (eds.), Wörterbücher. Dictionaries. Dictionnaires. Ein Internationales Handbuch zur Lexikographie, I, Berlin-New York (W. de Gruy-ter), pp. 673-680.

COSERIU, E. (1967/77), "Structure lexicale et enseignement du vocabulaire", en Conseil de la coopération culturelle du Conseil de l'Europe 1967: 9-87. Citamos por COSERIU, E., Principios de semántica estructural, Madrid (Gredos) 1977, pp. 87142.

DODD, S. (1994), “Tendencias en la lexicografía anglosajona: Los diccionarios monolingües para usuarios extranjeros", en HERNÁNDEZ 1994: 39-59.

DUBOIS, J. et al. (1973), Dictionnaire de linguistique, Paris (Larousse).

FLYDAL, L. (1951) ,"Remarques sur certains rapports entre le style et l'état de lan-

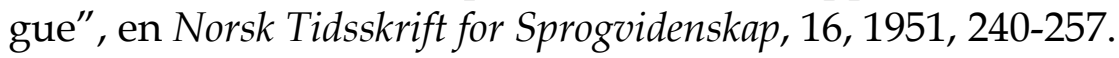

GARRIGA, C. (1994), "Las marca de 'vulgar' en el DRAE: de AUTORIDADES a 1992", Sintagma 6, 1994, 5-13.

GARRIGA, C. (1994-95), "Las marcas de uso: despectivo en el DRAE”, Revista de Lexicografía 1, Universidade da Coruña, 1994-95, 113-147.

GARRIGA, C. (1996), "La marca de irónico en el DRAE. de Autoridades a 1992", en Léxico y diccionarios (E. Forgas, coord.), Tarragona (Departament de Filologies Romàniques), pp.105-131.

GARRIGA, C. (1997), “Las 'marcas de uso' en los diccionarios del español”, Revista de Investigación Lingüística, nº 1, Universidad de Murcia, 1997, pp.75-110.

GARRIGA, C. (1999), "El 'registro familiar' como marca lexicográfica”, en Estudios de sociolingüística. Sincronía y diacronía II (P. Díez de Revenga y J.M ${ }^{a}$ Jiménez Cano, eds.), Murcia (DM), pp. 141-172.

\footnotetext{
${ }^{38}$ Asimismo, bajo el prisma de un soporte informático podría tener mayores posibilidades la realización de un diccionario estructural.
} 
GLATIGNY, M. (1989) "Les comentaires normatifs dans le dictionnaire monolingue", en HAUSSMANN, F.J. et al. (eds.), Wörterbücher. Dictionaries. Dictionnaires. Ein Internationales Hand-buch zur Lexikographie I, Berlin-New York (W. de Gruyter), pp.700-704.

HAENSCH, G. / WOLF, L. / ETTINGER, S. \& WERNER, R. (1982), La lexicografía. De la lingüística teórica a la lexicografía práctica, Madrid (Gredos).

HAENSCH, G. (1997), Los diccionarios del español en el umbral del siglo XXI; Salamanca (Ediciones Universidad de Salamanca).

HAUSSMANN, F.J. (1989), “Die Markierung im allgemeinen einsprachigen Wörterbuch: eine Übersicht", en HAUSSMANN, F.J. et al. (eds.), Wörterbücher. Dictionaries. Dictionnaires. Ein Internationales Handbuch zur Lexikographie I, Berlin-New York (W. de Gruyter), pp.649-657.

HAUSSMANN, F.J. et al. (eds.) (1989), Wörterbücher. Dictionaries. Dictionnaires. Ein Internationales Handbuch zur Lexikographie I, Berlin-New York (W. de Gruyter).

HERNÁNDEZ, H. (coord.) (1994), Aspectos de lexicografía contemporánea, Barcelona (Biblograf).

JAKOBSON, R. (1980/81), Dialogues (conv. con K. Pomorska), Paris: Flammarion. Citamos por la traducción española: Lingüística, poética, tiempo, Barcelona (Ed. Crítica), 1981.

KALVERKÄMPER, H. (1989), “Diatechnische Markierungen im allgemeinen einsprachigen Wörterbuch", en HAUSSMANN, F.J. et al. (eds.), Wörterbücher. Dictionaries. Dictionnaires. Ein Internationales Handbuch zur Lexikographie I, Berlin-New York (W. de Gruyter), pp.680-688.

LAGANE, R. (1969), "Le français commun, mythe ou réalité", Le français dans le monde, 69, dic. 1969, pp.6-11.

LEHMANN, A. (1993), “Le renouvellement de la lexicographie contemporaine dans le dictionnaire d'apprentissage: le cas du Robert des Jeunes", Actes du XXe Congrès International de Linguistique et Philologie Romanes, IV, Tubinga-Basel (Francke Verlag).

MARTINET, A. (1957) (bajo la dirección), La notion de neutralisation dans la morphologie et le lexique, Travaux de l' Institute de Linguistique, vol. II, Paris (Klincksieck).

MOUNIN, G. (1974/79), Dictionnaire de la Linguistique, Paris: Presses Universitaires de France. Citamos por la traducción española: Diccionario de Lingüística, Barcelona (Labor).

NIEBAUM, H. (1989), "Diatopische Markierungen im allgemeinen einsprachigen Wörterbuch", en HAUSSMANN, F.J. et al. (eds.), Wörterbücher. Dictionaries. Dictionnaires. Ein Internationales Handbuch zur Lexikographie, I, Berlin-New York (W. de Gruy-ter), pp.662-668.

PÜSCHEL, U. (1989), “Evaluative Markierungen im allgemeinen einsprachigen Wörterbuch", en HAUSSMANN, F.J. et al. (eds.), Wörterbücher. Dictionaries. Dic- 
tionnaires. Ein Internationales Handbuch zur Lexikographie, I, Berlin-New York (W. de Gruy-ter), pp.693-699.

REY-DEBOVE, J. (1971), Étude linguistique et sémiotique des dictionnaires français contemporains, The Hague (Mouton).

RODRÍGUEZ DÍEZ, B. (1981), Las Lenguas Especiales. El Léxico del Ciclismo, León (Colegio Universitario de León).

RODRÍGUEZ DÍEZ, B. (1997), El recurso a la neutralización en lingüística, León (CEMIUniversidad de León).

SCHAEDER, B. (1989), "Diafrequente Markierungen im allgemeinen einsprachigen Wörterbuch", en HAUSSMANN, F.J. et al. (eds.), Wörterbücher. Dictionaries. Dictionnaires. Ein Internationales Handbuch zur Lexikographie, I, Berlin-New York (W. de Gruy-ter), pp.688-693.

SCHMIDT, G.D. (1989), “Diachronische Markierungen im allgemeinen einsprachigen Wörterbuch", en HAUSSMANN, F.J. et al. (eds.), Wörterbücher. Dictionaries. Dictionnaires. Ein Internationales Handbuch zur Lexikographie, I, Berlin-New York (W. de Gruyter), pp.657-668.

SECO, M. (1977), "Problemas formales de la definición lexicográfica", Estudios ofrecidos a Emilio Alarcos Llorach, vol. 2, Oviedo (Universidad de Oviedo), pp.217-239.

WEINREICH, U. (1967), "Lexicographic definition in descriptive Semantics", en Problems in Lexicography (F.W. Householder \& S. Saporta eds.), Bloomington (Indiana Univ.), 1967, pp.25-44.

\section{DICCIONARIOS}

Alcalá-VOX = ALVAR EZQUERRA, M. (1995), Diccionario para la enseñanza de la Lengua Española, Barcelona (Biblograf).

BASIC English = OGDEN, Ch. K. (1940), The General BASIC English Dictionary.

Collins COBUILD = SINCLAIR, Jh. et al. (1987), Collins COBUILD English Dictionary, $1^{\mathrm{a}}$ ed., Londres-Glasgow (Harper Collins).

Diccionario de Autoridades = REAL ACADEMIA ESPAÑOLA $(1726,1729,1732,1734$, 1737, 1739), Diccionario de la lengua castellana en que se explica el verdadero sentido de las voces, su naturaleza y calidad, con las phrases o modos de hablar, los proverbios o refranes, y otras cosas convenientes al uso de la lengua, 6 vols., Madrid (Imprenta de Francisco del Hierro).

DILE-CASARES = CASARES, J. (1959), Diccionario ideológico de la lengua española, $2^{\mathrm{a}}$ ed., Barcelona (Gustavo Gili).

DRAE-1992 = REAL ACADEMIA ESPAÑOLA (1992), Diccionario de la Lengua Española, $21^{\mathrm{a}}$ ed., Madrid (Espasa-Calpe).

DRAE-1992/95 = REAL ACADEMIA ESPAÑOLA (1992), Diccionario de la Lengua Española, 21 $1^{\mathrm{a}}$ ed., Madrid (Espasa-Calpe). Versión electrónica. 
DUE-MOLINER = MOLINER, M. (1975), Diccionario de uso del español, 2 vols., Madrid (Gredos).

Larousse Júnior 1989. Diccionario de la E.G.B., $2^{\mathrm{a}}$ ed., Barcelona (Larousse), 1989.

REAL ACADEMIA ESPAÑOLA (1970), Diccionario de la Lengua Española, 19a ed., Madrid (Espasa-Calpe).

REAL ACADEMIA ESPAÑOLA (2001), Diccionario de la Lengua Española, $22^{\mathrm{a}}$ ed., Madrid (Espasa-Calpe).

Robert des Jeunes = REY-DEBOVE, J. (1988/91), Le Robert des Jeunes. Dictionnaire de la Langue française, París (Dictionnaires Le Robert). (Este diccionario había aparecido en 1988 con el título de Petit Robert des Enfants).

SALAMANCA-Santillana = GUTIÉRREZ CUADRADO, J. (1996), Diccionario SALAMANCA de la lengua española, Madrid-Salamanca (Santillana-Universidad de Salamanca).

SM-Clave = MALDONADO GONZÁLEZ, C. (1997), Diccionario de uso del español actual, Madrid (SM).

Tesoro de Covarrubias = COVARRUBIAS, Sebastián de (1611-1977), Tesoro de la lengua castellana o española, Madrid (Imprenta de Luis Sánchez), 1611 / Madrid (Turner), 1977. 